\title{
NUMERICAL MODELLING OF FRACTURE IN POLYOLEFIN FIBRE REINFORCED CONCRETE SPECIMENS UNDER MIXED-MODE LOADING (I+II)
}

\author{
F. SUÁREZ*, J.C. GÁLVEZ ${ }^{\dagger}$, A. ENFEDAQUE ${ }^{\dagger}$ AND M.G. ALBERTI ${ }^{\dagger}$ \\ * Departamento de Ingeniería Mecánica y Minera. Universidad de Jaén \\ Campus Científico-Tecnológico de Linares. Avda. de la Universidad (Cinturón Sur) - Linares, Spain \\ e-mail: fsuarez@ujaen.es \\ ${ }^{\dagger}$ Departamento de Ingeniería Civil-Construcción. Universidad Politécnica de Madrid \\ E.T.S.I. Caminos, Canales y Puertos, C/ Profesor Aranguren s/n - Madrid, Spain \\ e-mail: jaime.galvez@upm.es, alejandro.enfedaque@upm.es, marcos.garcia@upm.es
}

Key words: Cohesive Fracture, Fibre Reinforced Concrete, Composites, Durability

\begin{abstract}
In the last decades, many researchers have focused their work on studying the behaviour of fibre-reinforced concrete (FRC). The appearance of specific recommendations in several Standards has boosted their usage and the interest in this technology. Apart from the traditional steel fibres, new materials are now studied as fibre-type reinforcement in structural concrete. This is the case of polyolefin, a polymer that has proved to be a suitable alternative that overcomes some of the drawbacks of steel, namely those related to corrosion processes, and keeps a good ductile behaviour providing structural strength to concrete against tensile stresses. Modelling fracture of FRC elements has also proved to be successful using trilinear softening functions, not only with polyolefin fibres, but also with steel and glass fibres. Nevertheless, these numerical models have been used to contrast only notched specimens under three-point bending symmetric loading. In this contribution, trilinear softening functions are used to model fracture in specimens in which crack initiates under a combination of modes I and II. Fracture is modelled by means of an embedded crack formulation based on the strong discontinuity approach. Two sets of experimental data are compared, one with specimens of the same size with different proportions of fibres and another one where, keeping the fibre proportion constant, the specimens are scaled up in order to analyse the size effect. In both sets of experimental results, the Load-CMOD diagrams fit reasonably well using trilinear softening functions, predicting with correction the maximum load and the shape of the diagram due to the influence of the fibres.
\end{abstract}

\section{INTRODUCTION}

The use of fibres as reinforcement of concrete is not new but has experienced a remarkable development in these years. In this field, the use of polymeric fibres has become of increasing interest [1-3], since they can be suitable in situations where steel fibres could be not recommended, such as cases where electric or magnetic fields may affect any usability aspect of the structural element.

More especifically, polyolefin has been studied in depth as a remarkably interesting polymer that, when used in the form of macro-fibres and in a proper proportion, improves the performance of concrete under tensile stresses in such a manner that it even allows using only these fibres as reinforcement in structural elements [4, 5]. 
In the past, this type of fibres have been analysed in detail, studying their performance with conventional vibrated concrete and selfcompacting concrete [6], their influence on the mechanical properties of concrete using various fibre proportions [7] and the influence of fibre orientation and distribution in the mix on its performance [8, 9], among other aspects. The numerical simulation of fracture in specimens of polyolefin-fibre reinforced concrete (PFRC) has also been studied in the past using the threepoint bending test on notched specimens [10], therefore always comparing tests where concrete damage develops under mode I conditions. In those cases, the tests could be successfully simulated using an embedded crack model based on the cohesive zone approach [11] and defining a trilinear softening function [12]. Nevertheless, fracture under a combination of modes I and II is not fully understood and several researchers have proposed different experimental tests [13-16] to study this issue and numerical models to reproduce them [17-19].

In this contribution, an embedded cohesive crack model combined with the use of a trilinear softening function is employed to simulate PFRC specimens where crack initiates under a combination of modes I and II. In the first place, the experimental work is briefly described, including the experimental setup and the materials characteristics. Then, the numerical work is detailed, giving a short description of the embedded crack formulation and defining the finite element model used in this study. Finally, the experimental and numerical results are compared and some conclusions presented.

\section{EXPERIMENTAL WORK}

\subsection{Materials and specimens}

Two sets of specimens are analysed, their proportionings are specified in Table 1 . The first set, composed by FC-3, FC-6 and FC-10, comprises specimens of fluid concrete with three fibre dosages: 3,6 and $10 \mathrm{~kg} / \mathrm{m}^{3}$ respectively, using $60 \mathrm{~mm}$ long fibres. The second set are specimens made with the same concrete propor- tioning, resulting in a self-compacting concrete (SCC), and the same fibre dosage $\left(10 \mathrm{~kg} / \mathrm{m}^{3}\right)$, but with different specimen sizes. In this second set, small specimens are identied by SCC-S, medium specimens by SCC-M and large specimens by SCC-L, in all cases the fibres are 48 $\mathrm{mm}$ long. Table 2 summarises all these details for convenience.

The first set is designed to analyse how different fibre dosages affect the trilinear softening function used in the numerical model, that will be described later. The second set will help to identify possible size effects in the fracture behaviour of PFRC specimens under mixed-mode loading and their influence on their numerical simulation. Finally, the use of fibres with different lengths may help identifying the effect of this parameter on the numerical modelling of damage in this type of composite materials.

\subsection{Experimental setup}

The specimens are tested using an experimental setup proposed in [16] and identified as type 1. This experimental setup can be seen as a variation of the classical three point bending test described by [10], where supports and load are now not disposed simmetrically, but as shown in Figure 1, this setup induces a stress state at the crack tip that leads to a fracture process that initiates with a combination of modes I and II.

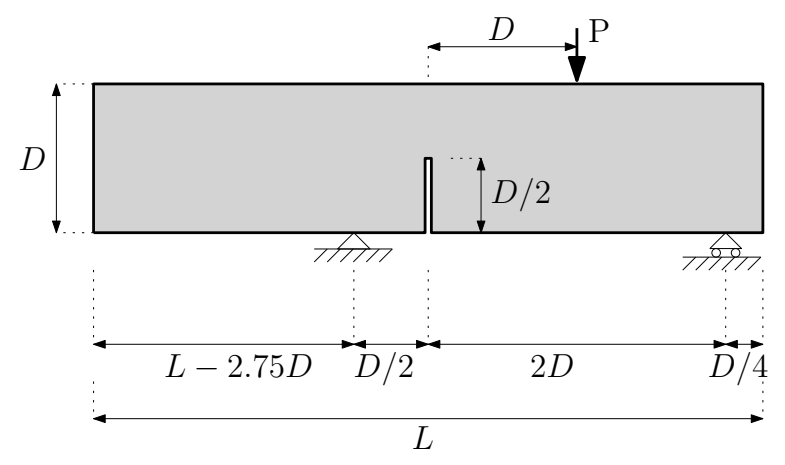

Figure 1: Setup of the type 1 three point bending test described in [16]. 
Table 1: Proportioning of each mix analysed in this study.

\begin{tabular}{|c|c|c|c|c|c|c|c|c|}
\hline & $\begin{array}{l}\text { Cement } \\
\left(\mathrm{kg} / \mathrm{m}^{3}\right)\end{array}$ & $\begin{array}{c}\text { Limestone } \\
\text { powder } \\
\left(\mathrm{kg} / \mathrm{m}^{3}\right)\end{array}$ & $\begin{array}{l}\text { Water } \\
\left(\mathrm{kg} / \mathrm{m}^{3}\right)\end{array}$ & $\left(\mathrm{kg} / \mathrm{m}^{3}\right)$ & $\left(\mathrm{kg} / \mathrm{m}^{3}\right)$ & $\begin{array}{c}\text { Grit } \\
\left(\mathrm{kg} / \mathrm{m}^{3}\right)\end{array}$ & $\begin{array}{l}\text { Superplasticizer } \\
\text { (\% cem. } \\
\text { weight) }\end{array}$ & $\begin{array}{l}\text { Polyolefin } \\
\text { fibres } \\
\left(\mathrm{kg} / \mathrm{m}^{3}\right)\end{array}$ \\
\hline FC-3 & 375 & 100 & 187.5 & 916 & 300 & 450 & 0.82 & 3 \\
\hline FC-6 & 375 & 100 & 187.5 & 916 & 300 & 450 & 0.82 & 6 \\
\hline FC-10 & 375 & 100 & 187.5 & 916 & 300 & 450 & 0.82 & 10 \\
\hline SCC & 375 & 200 & 187.5 & 918 & 367 & 245 & 1.25 & 10 \\
\hline
\end{tabular}

Table 2: Nomenclature, dimensions, concrete type and fibre lengths used for each set of specimens.

\begin{tabular}{|c|c|c|c|c|c|}
\hline \multirow[t]{2}{*}{ Nomenclature } & \multicolumn{3}{|c|}{ Dimensions $(\mathrm{mm})$} & \multirow{2}{*}{$\begin{array}{l}\text { Concrete type } \\
\text { type }\end{array}$} & \multirow{2}{*}{$\begin{array}{c}\text { Fibre } \\
\text { length }(\mathrm{mm})\end{array}$} \\
\hline & Length & Width & Height & & \\
\hline FC-3 & 600 & 150 & 150 & Fluid & 60 \\
\hline FC-6 & 600 & 150 & 150 & Fluid & 60 \\
\hline FC-10 & 600 & 150 & 150 & Fluid & 60 \\
\hline SCC-S & 340 & 50 & 75 & Self-compacting & 48 \\
\hline SCC-M & 675 & 50 & 150 & Self-compacting & 48 \\
\hline SCC-L & 1350 & 50 & 300 & Self-compacting & 48 \\
\hline
\end{tabular}

\section{NUMERICAL SIMULATION}

\subsection{Embedded cohesive crack formulation}

Fracture is numerically reproduced by means of an element formulation that simulates the initiation and development of an embedded crack. This formulation is based on the cohesive zone approach and its detailed description can be consulted in [20]; it has been successfully used to simulate fibre-reinforced concrete mixes under mode I conditions [21].

This formulation is a central forces model, that is to say, it assumes that the cohesive stress vector $t$ is perpendicular to the crack opening and parallel to the crack displacement vector $\boldsymbol{w}$ :

$$
\boldsymbol{t}=\frac{f(\tilde{w})}{\tilde{w}} \boldsymbol{w} \quad \text { with } \tilde{w}=\max (|\boldsymbol{w}|)
$$

with $f(|\tilde{w}|)$ representing the material softening function, which is expressed in terms of an equivalent crack opening $\tilde{w}$ that stores the maximum historical crack opening, which allows accounting for possible unloading processes. When simulating PFRC specimens, this softening function presents three linear branches [12] as shown in Figure 2, and can be expressed by:

$$
\sigma= \begin{cases}f_{c t}+\left(\frac{\sigma_{k}-f_{c t}}{w_{k}}\right) \cdot w & \text { if } 0<w \leq w_{k} \\ \sigma_{k}+\left(\frac{\sigma_{r}-\sigma_{k}}{w_{r}-w_{k}}\right) \cdot\left(w-w_{k}\right) & \text { if } w_{k}<w \leq w_{r} \\ \sigma_{r}+\left(\frac{-\sigma_{r}}{w_{f}-w_{r}}\right) \cdot\left(w-w_{r}\right) & \text { if } w_{r}<w \leq w_{f} \\ 0 & \text { if } w>w_{f}\end{cases}
$$

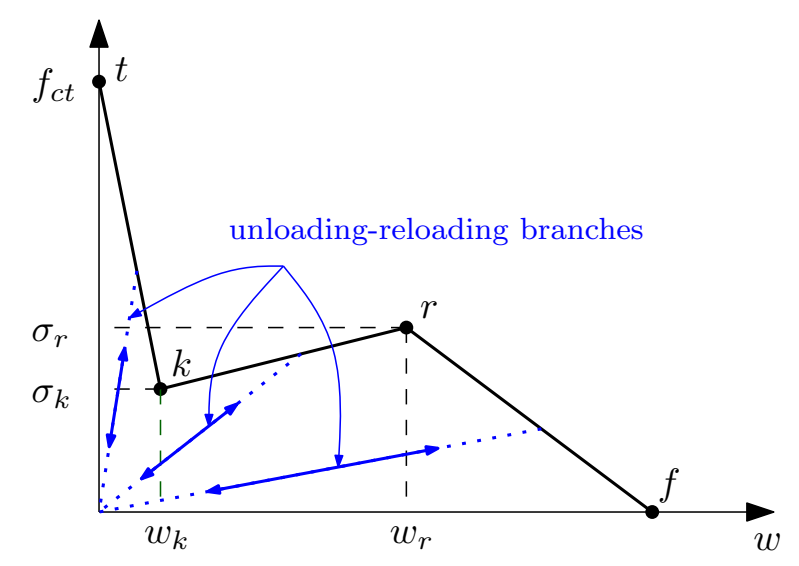

Figure 2: Trilinear softening function.

In the models that are presented later, constant strain triangular elements are used; in this case crack can only develop in directions parallel to one of the triangle sides and at mid 
height, which guarantees local and global equilibria and reduces to three the possible crack paths in an element (see Figure 3).

Once the cracking process starts, the element is divided into two parts, $\mathrm{A}^{+}$and $\mathrm{A}^{-}$. If $A$ stands for the element area, $h$ for the height of the triangle perpendicular to the opposite side to the solitary node, $L$ for the crack length and $\boldsymbol{n}$ for the unit vector perpendicular the the crack, vector $t$ is constant along the crack and can be obtained as:

$$
\boldsymbol{t}=\frac{A}{h L} \boldsymbol{\sigma} \cdot \boldsymbol{n}
$$

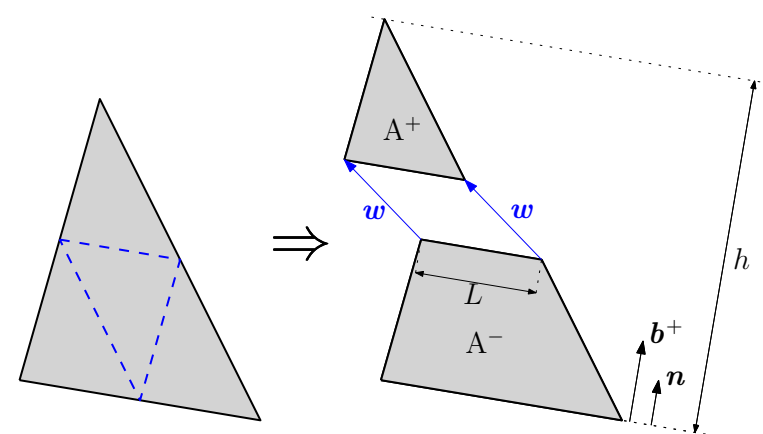

Figure 3: Potential crack paths (left) and geometrical definitions of $\boldsymbol{w}, \boldsymbol{n}$ and $\boldsymbol{b}^{+}$(right).

The part of the element outside the crack has a linear-elastic behaviour and the crack displacement vector $\boldsymbol{w}$ can be obtained substracting the contribution of the crack to the elastic prediction of the stress:

$$
\boldsymbol{\sigma}=\boldsymbol{E}:\left[\epsilon^{a}-\left(\boldsymbol{b}^{+} \otimes \boldsymbol{w}\right)^{S}\right]
$$

where $\boldsymbol{E}$ stands for the elastic tangent tensor, $\boldsymbol{b}^{+}$for the gradient vector of the solitary node shape function, expressed by (5), $\epsilon^{a}$ for the apparent strain vector. In this expression superscript $S$ indicates the symmetric part of the tensor, : the usual double-dot product $((\boldsymbol{A}$ : $\left.\boldsymbol{b})_{i j}=A_{i j k l} b_{k l}\right)$ and $\otimes$ the usual direct product $\left((\boldsymbol{a} \otimes \boldsymbol{b})_{i j}=a_{i} b_{j}\right)$.

$$
\boldsymbol{b}^{+}=\frac{1}{h} \boldsymbol{n}
$$

In addition, $\boldsymbol{t}$ can be obtained as $\boldsymbol{t}=\boldsymbol{\sigma} \cdot \boldsymbol{n}$, by using (1) and (4):

$$
\frac{f(\tilde{w})}{\tilde{w}} \boldsymbol{w}=\left[\boldsymbol{E}: \boldsymbol{\epsilon}^{a}\right] \cdot \boldsymbol{n}-\left[\boldsymbol{E}:\left(\boldsymbol{b}^{+} \otimes \boldsymbol{w}\right)^{S}\right] \cdot \boldsymbol{n}
$$

which can be rewritten as:

$$
\left[\frac{f(\tilde{w})}{\tilde{w}} \mathbf{1}+\boldsymbol{n} \cdot \boldsymbol{E} \cdot \boldsymbol{b}^{+}\right] \cdot \boldsymbol{w}=\left[\boldsymbol{E}: \boldsymbol{\epsilon}^{a}\right] \cdot \boldsymbol{n}
$$

with 1 being the second-order identity tensor.

\subsection{Numerical models}

The experimental results have been numerically reproduced by means of the Finite Element Method (FEM) with the commercial software Abaqus ${ }^{\circledR}$. These models are bidimensional and the formulation described above has been implemented using a UMAT user subroutine written in Fortran. The models are discretised with reduced integration triangular elements, which is required by the formulation presented above. In order to compare the numerical results with the experimental data, the Load-CMOD diagrams are displayed. It must be noted that since the experimental setup induces a non-symmetrical deformed shape of the specimen, the CMOD is affected not only by the horizontal displacements, but also by the vertical displacements. This is experimentally done by using a strain gauge that measures the displacement between the points at the end of the notch and must be carefully considered when obtaining the diagrams of the numerical models (see Figure 4).

In regard to the softening functions, Tables 3 and 4 show the characteristic points of the trilinear softening functions used in each case, which are depicted in Figure 5

In the case of the FC specimens, points $t$ and $f$ have been fixed and only intermediate points $k$ and $r$ have been modified to adjust the material behaviour to different fibre dosages. In the case of SCC specimens, the same softening function has been used because all specimens have the same fibre dosage. 


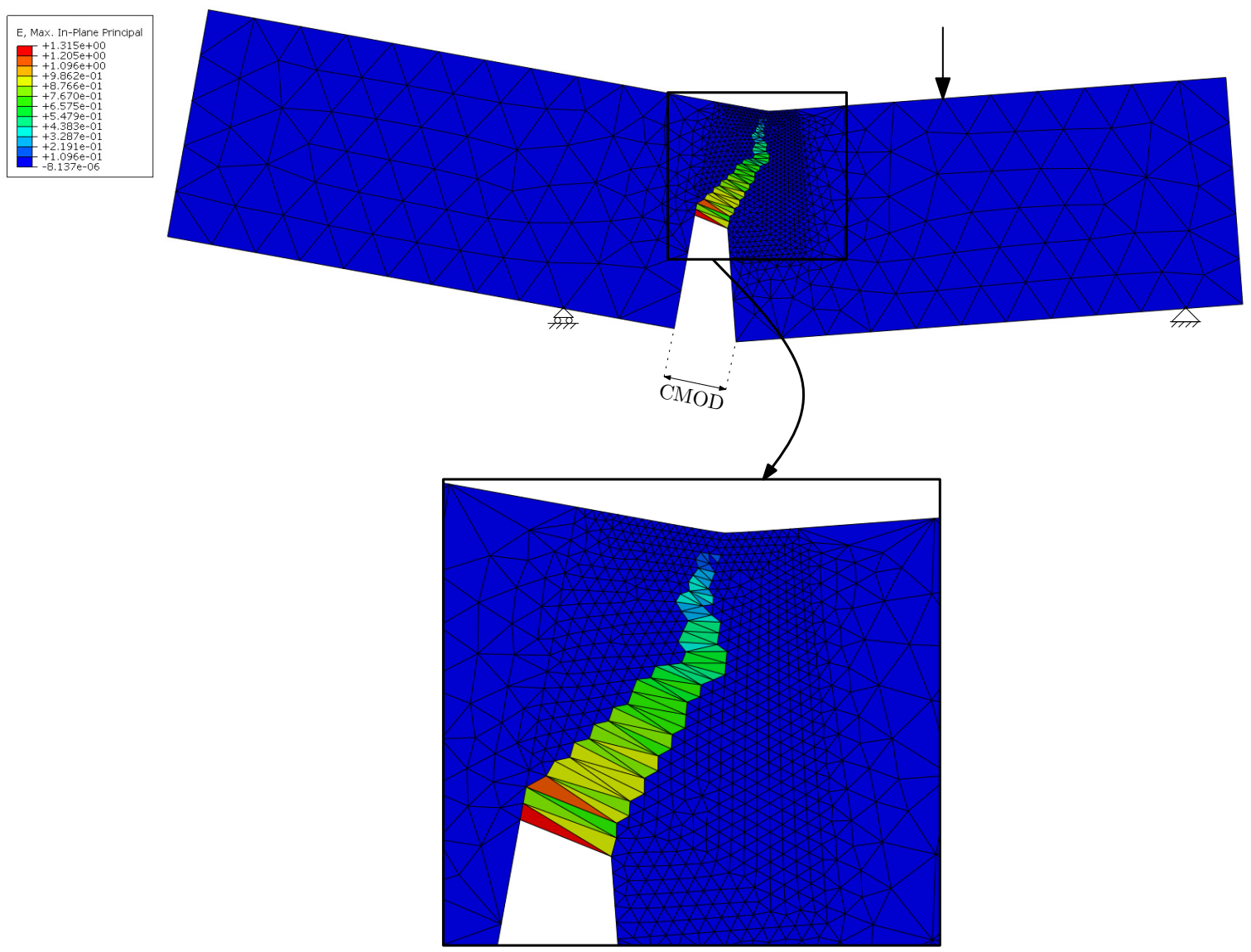

Figure 4: Map of stresses of the SCC-L model and a detail of the crack path.

Table 3: Characteristic points of the trilinear softening functions used with the fluid concrete mixes.

\begin{tabular}{|c|c|c|c|c|c|c|c|c|c|c|c|c|}
\hline & \multicolumn{4}{|c|}{ FC-3 } & \multicolumn{4}{|c|}{ FC-6 } & \multicolumn{4}{|c|}{ FC-10 } \\
\hline & $t$ & $k$ & $r$ & $f$ & $t$ & $k$ & $r$ & $f$ & $t$ & $k$ & $r$ & $f$ \\
\hline$w(\mathrm{~mm})$ & 0.00 & 0.15 & 2.250 & 7.50 & 0.00 & 0.14 & 2.250 & 7.50 & 0.00 & 0.13 & 2.250 & 7.50 \\
\hline$\sigma(\mathrm{MPa})$ & 2.30 & 0.12 & 0.245 & 0.00 & 2.30 & 0.33 & 0.700 & 0.00 & 2.30 & 0.75 & 1.700 & 0.00 \\
\hline
\end{tabular}

Table 4: Characteristic points of the trilinear softening functions used with the sef-compacting concrete mixes.

\begin{tabular}{ccccc}
\hline & \multicolumn{4}{c}{ SCC } \\
\cline { 2 - 5 } & $t$ & $k$ & $r$ & $f$ \\
\hline$w(\mathrm{~mm})$ & 0.000 & 0.070 & 1.650 & 7.500 \\
$\sigma(\mathrm{MPa})$ & 3.000 & 0.570 & 1.050 & 0.000 \\
\hline
\end{tabular}




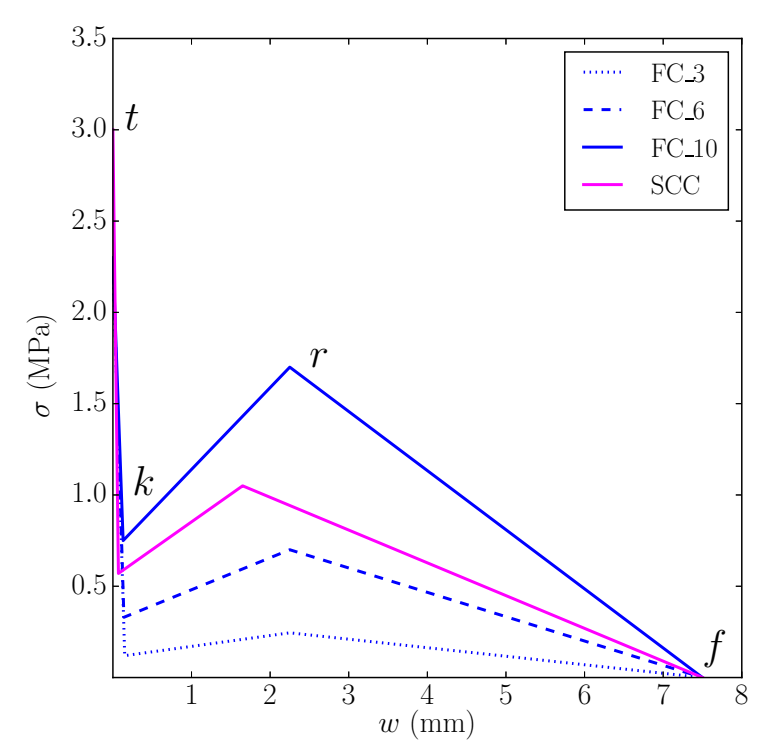

Figure 5: Softening functions used with each PFRC mix.

\section{RESULTS}

Figures 6 and 7 show the results for the fluid concrete specimens (FC) with different fibre dosages and the self-compacting concrete specimens (SCC) of different sizes, respectively. The experimental curves are represented with dashed lines and the numerical results with continuous lines.

In the case of FC specimens, the peak load is reproduced with accuracy in all cases and the subsequent behaviour is also correctly captured. The load increase after the peak as well as the following decrease are always inside the experimental envelope and correctly reproduce the contribution of fibres in all cases. It is interesting to note how the softening function varies with increasing dosages of fibres. Point $k$ must be defined at smaller values of $w$ for higher contents of fibres because the load decrease is smaller when more fibres are present in the mix, but always following the same straight line in the unloading branch $t-k$. As for point $r$, the value of $\sigma$ is higher when the fibre dosage is higher in order to account for the greater load recovery that fibres provide, but always at the same value of $w$.

If the results of SCC specimens are observed, the experimental results are also well reproduced by the FEM models. It must be noted that the same softening function has been used for all specimen sizes, thus not showing any evident size effect, at least with the sizes considered in this study. It is also interesting to observe that the initial point of the softening function $t$ is not the same as that of the FC specimen, which is probably because the tensile strength of each concrete proportioning is different.

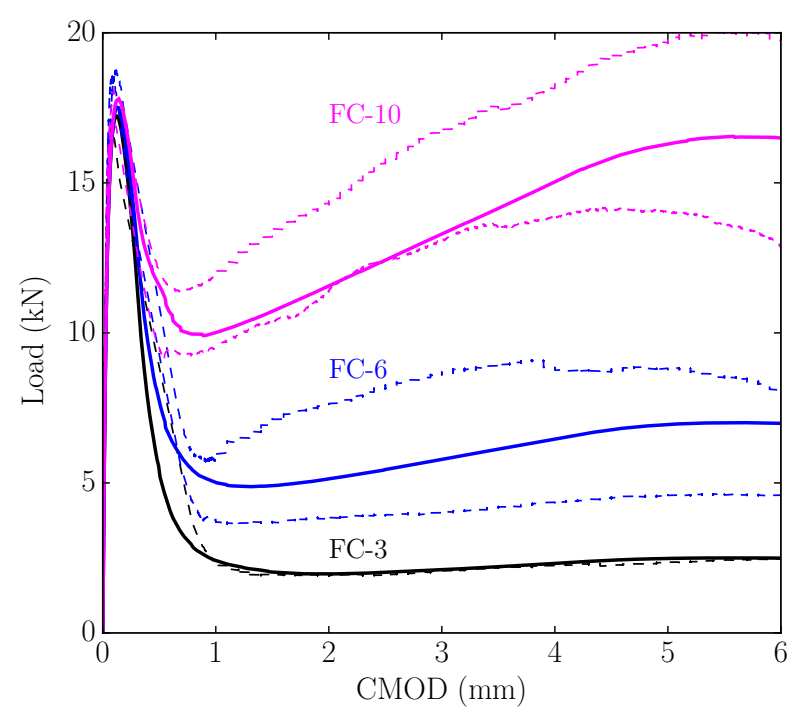

Figure 6: Load-CMOD diagrams for the fluid concrete specimens and simulations.

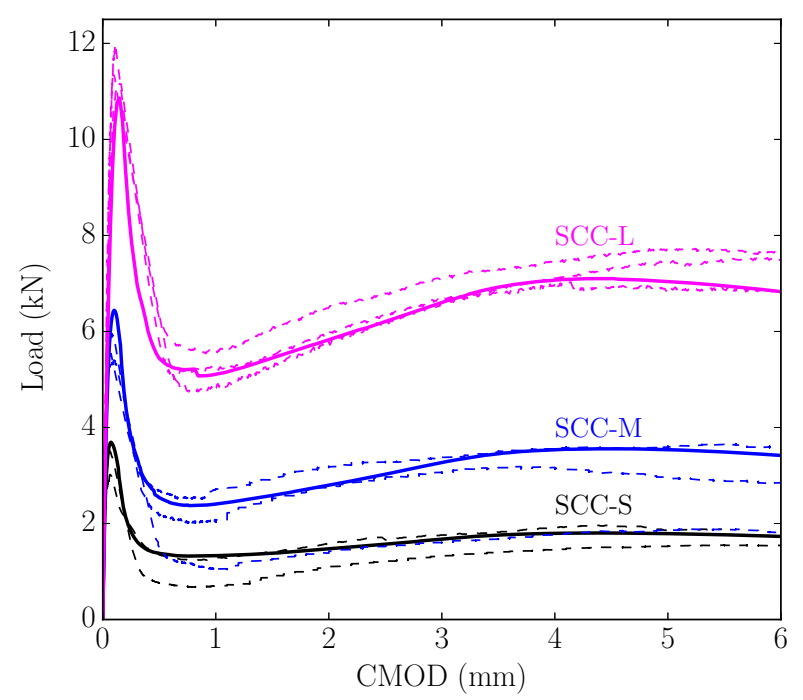

Figure 7: Load-CMOD diagrams for the selfcompacting concrete specimens and simulations. 
Finally, it is interesting to observe that point $r$ has been defined at a smaller value of $w$ in these specimens. Point $r$ identifies the crack opening at which the fibres reduce their effectiveness, thus, this behaviour can be related to the fibre length, which is smaller than in the case of FC specimens.

\section{CONCLUSIONS}

- An embedded cohesive model based on the central forces approach has provided numerical results that reproduce with accuracy the experimental results for PFRC specimens under mixed-mode fracture loading.

- The use of trilinear softening functions with the cohesive crack concept can correctly simulate the influence of fibres inside concrete under mixed-mode fracture conditions.

- The values of the characteristic points of the trilinear softening function must be adjusted for each concrete proportioning, but its correction for different fibre dosages can be easily carried out.

- For higher fibre dosages, point $r$ must be modified keeping the value of $w$ and $k$ must be modified keeping the slope of the unloading branch $t-k$.

- The same softening function can be used with different sizes specimens made of the same PFRC proportioning.

\section{Acknowledgements}

This work has been supported by the Ministry of Economy and Competitiveness of Spain under the Research Fund Project BIA201678742-C2-2-R. The authors also wish to express their gratitude to SIKA SAU for supplying the polyolefin fibres used in the experimental work.

\section{REFERENCES}

[1] Khalid FS, Irwan JM, Ibrahim MHW, Othman N, Shahidan S. Performance of plastic wastes in fiber-reinforced concrete beams. Construction and Building Materials. 2018;183:451 - 464.

[2] Banthia N, Gupta R. Influence of polypropylene fiber geometry on plastic shrinkage cracking in concrete. Cement and Concrete Research. 2006;36(7):1263 $-1267$.

[3] Li B, Chi Y, Xu L, Shi Y, Li C. Experimental investigation on the flexural behavior of steel-polypropylene hybrid fiber reinforced concrete. Construction and Building Materials. 2018;191:80 - 94.

[4] Alberti MG, Gálvez JC, Enfedaque A, Carmona A, Valverde C, Pardo G. Use of Steel and Polyolefin Fibres in the $\mathrm{La}$ Canda Tunnels: Applying MIVES for Assessing Sustainability Evaluation. Sustainability. 2018;10(12):4765.

[5] Enfedaque A, Alberti M, Gálvez J, Rivera M, Simón-Talero J. Can Polyolefin Fibre Reinforced Concrete Improve the Sustainability of a Flyover Bridge? Sustainability. 2018;10(12):4583.

[6] Alberti MG, Enfedaque A, Gálvez JC. Comparison between polyolefin fibre reinforced vibrated conventional concrete and self-compacting concrete. Construction and Building Materials. 2015;85:182 194.

[7] Alberti MG, Enfedaque A, Gálvez JC. On the mechanical properties and fracture behavior of polyolefin fiber-reinforced selfcompacting concrete. Construction and Building Materials. 2014;55:274 - 288.

[8] Alberti MG, Enfedaque A, Gálvez JC, Ferreras A. Pull-out behaviour and interface critical parameters of polyolefin fibres embedded in mortar and self-compacting concrete matrixes. Construction and Building Materials. 2016;112:607 - 622 . 
[9] Alberti MG, Enfedaque A, Gálvez JC, Agrawal V. Fibre distribution and orientation of macro-synthetic polyolefin fibre reinforced concrete elements. Construction and Building Materials. 2016;122:505 517.

[10] RILEM. Determination of the Fracture Energy of Mortar and Concrete by Means of Three-Point Bend Tests on Notched Beams. Materials and Structures. 1985;18(106):285-290.

[11] Gálvez JC, Planas J, Sancho JM, Reyes E, Cendón DA, Casati MJ. An embedded cohesive crack model for finite element analysis of quasi-brittle materials. Engineering Fracture Mechanics. 2013;109:369386.

[12] Alberti MG, Enfedaque A, Gálvez JC, Reyes E. Numerical modelling of the fracture of polyolefin fibre reinforced concrete by using a cohesive fracture approach. Composites Part B: Engineering. 2017;111:200 - 210 .

[13] Ingraffea A, Arrea M. Mixed-Mode Crack Propagation in Mortar and Concrete. Dept. of Structural Engineering. Cornell University, USA; 1982.

[14] Bažant Z, Pfeiffer P. Shear fracture tests of concrete. Materials and Structures. 1986;19(2):111-121.

[15] Nooru-Mohamed MB. Mixed-mode fracture of concrete: an experimental ap- proach. Doctoral Dissertation. Delft University of Technology; 1992.

[16] Gálvez JC, Elices M, Guinea G, Planas J. Mixed mode fracture of concrete under proportional and nonproportional loading. International Journal of Fracture. 1998;94(3):267-284.

[17] Garcia-Alvarez VO, Gettu R, Carol I. Analysis of mixed-mode fracture in concrete using interface elements and a cohesive crack model. Sadhana. 2012;37(1):187-205.

[18] Suárez F, Gálvez J, Cendón D. A material model to reproduce mixed-mode fracture in concrete. Fatigue \& Fracture of Engineering Materials \& Structures. 2019;42(1):223-238.

[19] Suárez F, Gálvez JC, Enfedaque A, Alberti MG. Modelling fracture on polyolefin fibre reinforced concrete specimens subjected to mixed-mode loading. Engineering Fracture Mechanics. 2019;211:244 253.

[20] Sancho JM, Planas J, Cendón DA, Reyes E, Gálvez JC. An embedded crack model for finite element analysis of concrete fracture. Engineering Fracture Mechanics. 2007;74(1):75 - 86 .

[21] Enfedaque A, Alberti MG, Gálvez JC, Domingo J. Numerical simulation of the fracture behaviour of glass fibre reinforced cement. Construction and Building Materials. 2017;136:108 - 117. 